\title{
Validation of the new Vancouver Chest Pain Rule in Asian chest pain patients presenting at the emergency department
}

\author{
Marcus Eng Hock Ong, MBBS, MPh*§; Ying Hao, $\mathrm{PhD}^{\dagger}$; Susan Yap, RN*; Pin Pin Pek, PgDip*; \\ Terrance Siang Jin Chua, MBBS ${ }^{\ddagger \pi}$; Faith Suan Peng Ng, MAppStat**; Swee Han Lim, MBBS*
}

\section{ABSTRACT}

Objectives: The new Vancouver Chest Pain (VCP) Rule recommends early discharge for chest pain patients who are at low risk of developing acute coronary syndrome (ACS), and thus can be discharged within 2 hours of arrival at the emergency department (ED). This study aimed to assess the performance of the new VCP Rule for Asian patients presenting with chest pain at the ED.

Methods: This prospective cohort study involved patients attended to at the ED of a large urban centre. Patients of at least 25 years old, presenting with stable chest pain and a non-diagnostic ECG, and with no history of active coronary artery disease were included in the study. The main outcome measures were cardiac events, angioplasty, or coronary artery bypass within 30 days of enrolment.

Results: The study included 1690 patients from 27 August 2000 to 1 May 2002, with 661 patients fulfilling the VCP criteria. Of those for early discharge, 24 had cardiac events and 13 had angioplasty or bypass at 30 days, compared to 91 and 41, respectively, for those unsuitable for discharge. This gave the rule a sensitivity of $78.1 \%$ for cardiac events, including angioplasty and bypass. Specificity was $41.0 \%$, and negative predictive value (NPV) was $94.4 \%$.

Conclusion: We found the new VCP Rule to have moderate sensitivity and poor specificity for adverse cardiac events in our population. With an NPV of less than $100 \%$, this means that a small proportion of patients sent home with early discharge would still have adverse cardiac events.

\section{RÉSUMÉ}

Objectifs: Selon la nouvelle règle de Vancouver sur la douleur thoracique, il est recommandé que les patients qui présentent des douleurs thoraciques mais qui connaissent un faible risque de syndrome coronarien aigu puissent être renvoyés peu de temps après leur arrivée au service des urgences (SU), soit dans les deux heures suivantes. L'étude visait à évaluer la performance de la nouvelle règle de Vancouver chez des patients d'origine asiatique présentant des douleurs thoraciques, au SU.

Méthode: II s'agit d'une étude de cohorte, prospective, à laquelle ont participé des patients traités dans un SU d'un important centre urbain. Ont été sélectionnés des patients âgés d'au moins 25 ans, qui présentaient une douleur thoracique stable mais chez qui l'ECG s'est révélé non concluant et qui n'avaient pas d'antécédents de coronaropathie active. Les principaux critères d'évaluation consistaient en la survenue d'événements cardiaques ou encore en la réalisation d'une angioplastie ou d'un pontage coronarien dans les 30 jours suivant l'inclusion dans l'étude.

Résultats: Au total, 1690 patients ont participé à l'étude, du 27 août 2000 au $1^{\mathrm{er}}$ mai 2002, dont 661 répondaient aux critères de la nouvelle règle de Vancouver. Parmi ceux qui ont été renvoyés peu de temps après leur arrivée, 24 ont subi un événement cardiaque et 13 autres, une angioplastie ou un pontage coronarien au bout de 30 jours contre 91 et 41 respectivement parmi ceux qui n'étaient pas en état de quitter I'hôpital. Ainsi, la sensibilité de la règle s'est établie à $78,1 \%$ à l'égard des événements cardiaques, y compris de l'angioplastie et du pontage coronarien; la spécificité, à $41,0 \%$ et la valeur prédictive négative (VPN), à 94,4 \%.

Conclusions: Les auteurs sont arrivés à la conclusion que la nouvelle règle de Vancouver avait une sensibilité moyenne et une faible spécificité à l'égard des événements cardiaques défavorables dans la population étudiée. Du fait que la VPN est inférieure à $100 \%$, une faible proportion de patients renvoyés à domicile peu de temps après leur arrivée au SU sont susceptibles de subir des événements cardiaques défavorables.

Keywords: acute coronary syndrome, chest pain, clinical decision rules, emergency department, Vancouver Chest Pain Rule

From the *Department of Emergency Medicine, †Division of Research, and $¥$ National Heart Centre Singapore, Singapore General Hospital Singapore, §Health Services and Systems Research, Duke-NUS Graduate Medical School, Singapore, ๆSingapore Health Services, Singapore; and the **Department of Ophthalmology, Tan Tock Seng Hospital, Singapore.

Correspondence to: Marcus Eng Hock Ong, Department of Emergency Medicine, Singapore General Hospital, Outram Road, Singapore 169608; Email: marcus.ong.e.h@sgh.com.sg 


\section{INTRODUCTION}

In the United States, more than two million patients are hospitalized annually because of chest pain suggestive of myocardial ischemia. However, a coronary event is demonstrated in $<20 \%$ of this population. ${ }^{1}$ Accurate identification of the cause of acute chest pain is a challenge to emergency physicians. Previous studies show that about $2 \%-8 \%$ of patients with acute myocardial infarction (AMI) were discharged from emergency departments (EDs) inadvertently. ${ }^{2}$ Out of these, approximately $25 \%$ may develop adverse cardiac events before returning to the hospital. ${ }^{3}$ The desire for sensitivity in evaluating chest pain patients has led to their undergoing prolonged ED observation, admission and/or non-invasive or invasive testing, despite a low overall event rate. Multiple rapid-rule-out protocols have been developed to facilitate rapid ED discharge of low-risk patients. ${ }^{4-7}$ Two surveys done with physicians showed that acceptable miss-rate for AMI was between $1 \%$ and $2 \%$ for these rapid rule-out protocols. ${ }^{8-9}$

The Vancouver Chest Pain (VCP) Rule recommends early discharge for a group of patients who are at low risk of adverse events to be discharged within 2 hours of ED arrival. ${ }^{4}$ The main cardiac enzyme marker used in the original VCP Rule was creatinine kinase - muscle/ brain isomer (CK-MB). However, as troponin assays have improved in their sensitivity and precision over the years, ${ }^{10-11}$ recent studies have replaced CK-MB with troponin as the cardiac enzyme marker in the VCP Rule. ${ }^{5,6}$ Greenslade et al. ${ }^{5}$ recommended modifying the VCP Rule if troponin was to be used as the only biomarker.

The new VCP Rule was subsequently developed by Scheuermeyer and team, ${ }^{7}$ where the rule stated that for early discharge of chest pain patients, patients needed to have 1) a normal initial electrocardiogram (ECG), troponin $\leq 99 \%$ at 2 hours, no previous known history of acute coronary syndrome (ACS) or nitrate use and chest pain increasing with palpation; or 2) a normal initial ECG, troponin $\leq 99 \%$ at 2 hours, no previous known history of ACS or nitrate use, chest pain not increasing with palpation, age $<50$ years old, and nonradiating pain (neck, jaw, or arm). Cullen et al. ${ }^{6}$ further validated the study and found $99.1 \%$ sensitivity and $16.3 \%$ specificity. However, these studies were all conducted in a Caucasian population; there have been no other similar validation studies of the new VCP Rule in the Asian population.

\section{OBJECTIVES}

We thus aimed to assess the performance of the VCP Rule for Asian patients presenting with chest pain at the ED. We specifically looked at the sensitivity, specificity, positive predictive value (PPV), negative predictive value (NPV), and admission rates when applying these rules in a local setting.

\section{MATERIALS AND METHODS}

This study is a secondary analysis of a prospective data set, which involved a randomized controlled trial (RCT) comparing stress myocardial perfusion imaging (SMPI) for chest pain patients. ${ }^{12}$ In the RCT, eligible patients were randomized into the intervention (SMPI) or control (clinical assessment) protocol at presentation in the ED. Randomization was 2:1 for SMPI versus clinical assessment. The population was chest pain patients presenting to the ED Chest Pain Unit in a large urban centre from 27 August 2000 to 1 May 2002. The Hospital Ethics Board approval was obtained for the study.

The Singapore General Hospital (SGH) is Singapore's oldest and largest acute tertiary hospital and national referral centre. SGH accounts for about one third of total acute hospital beds in the public sector and about a quarter of acute beds nationwide. Annually, about 60,000 patients are admitted to our wards and another 600,000 attend to our specialist outpatient clinics. The ED sees approximately 300 to 500 visits a day.

Patients were admitted to the chest pain unit and included in the study if they were at least 25 years of age, presented to the ED with stable chest pain and with an initial 12-lead ECG non-diagnostic for myocardial ischemia and AMI. There was no lower age limit if the patient had any coronary risk factors such as diabetes mellitus or family history of young AMI (less than 50 years old). Written informed consent was taken from these patients.

Patients were excluded if the ECG was diagnostic for AMI or acute myocardial ischemia (which was defined as new $\mathrm{Q}$ wave, ST elevation, or depression greater than $1 \mathrm{~mm}$ or $0.1 \mathrm{mV}$ in two or more contiguous leads), or if there was congestive cardiac failure or hypotension associated with chest pain. If a clinical syndrome of persistent chest pain consistent with unstable angina was present, these patients were admitted to the coronary care unit or a telemetry bed and were 
excluded. Also excluded were patients with a past history of proven coronary artery disease, and presenting with chest pain that was more severe or frequent than previous angina episodes.

Once the patient was enrolled, he or she was put on continuous ECG monitoring, and $10 \mathrm{ml}$ of blood was drawn at $0,3,6$ hours after arrival at the ED for myoglobin, CK-MB (Elecsys CK-MB STAT assay), and TnT (3rd Generation Elecsys Troponin T STAT assay) analysis. Previous hospital case record and ECGs of the patient, if available, were retrieved. A detailed prospective collection of presenting history, examination, ECG, and laboratory results was done by dedicated research coordinators as part of the larger RCT. This included results of subsequent admissions, stress testing, angiography, and clinical outcomes. Follow-up medical case records of all participants were reviewed, and participants were followed up at 1 week, 2 weeks, 1 month, and 6 months for any adverse cardiac events such as cardiac-related death, ventricular fibrillation, and myocardial infarction. Patients were contacted by phone at 1 week, 2 weeks, 1 month, and 6 months after discharge for measurement of adverse cardiac events (primary end point). Patients who could not be contacted by phone were contacted by letter. If the patients could not be contacted, records from the Registry of Deaths were screened to trace for the final outcomes.

The VCP Rule was then applied retrospectively to this cohort of chest pain patients, and they were categorized as unsuitable or suitable for early discharge based on the rule.

\section{Outcomes}

All cases with missing data at decision points were assigned as unsuitable for early discharge. The main outcome measures were cardiac events (death, ventricular fibrillation, myocardial infarction, cardiogenic shock, or acute pulmonary edema), angioplasty, or coronary artery bypass within 30 days of enrolment.

\section{Statistical analysis}

All analyses were done using $\mathrm{R}$ 3.0.2. In the descriptive analysis, the differences in qualitative outcomes were determined using the chi-square and the Fisher exact tests. A two-sample t-test was performed when normality and homogeneity assumptions were satisfied; otherwise, the non-parametric Mann-Whitney $U$ test was used for quantitative outcomes. Sensitivity, specificity, PPV, and NPV were calculated where appropriate.

\section{RESULTS}

A total of 1690 eligible chest pain patients presented to the ED between 27 August 2000 and 1 May 2002.

Table 1 shows the characteristics of the patients enrolled in the study. Mean age was 53.0 years (SD 12.5), with 59.2\% males; 69.8\% were Chinese, $11.3 \%$ Malays, $17.3 \%$ Indian, and $1.7 \%$ other races. The patient's medical history and clinical presentation are also shown.

Figure 1 shows the characteristics of the patients according to the VCP Rule; 661 patients were found to fulfil the VCP criteria for low risk and early discharge. This gave an "early" discharge rate of $39 \%$ for the chest pain cohort. According to the rule, 331 (19.6\%) patients would have avoided blood testing and 311 (18.4\%) needed one TnT test only. However, we noted that, in this study, a second TnT was taken 3 hours after the first sample (instead of 2 hours in the original rule); 19 (1.1\%) patients of at least 50 years old had an initial TnT $>/=0.03 \mathrm{ng} / \mathrm{ml}$ but no ECG or serum-marker increase at 3 hours. These patients would still have waited $>4$ hours before "early" discharge, factoring in the wait time needed to obtain laboratory results.

Table 2 shows the 7-day and 30-day cardiac events of the entire patient cohort. AMI $(6.5 \%$ v. $6.7 \%$ for 7 -day and 30-day cardiac events, respectively) was the most common cardiac event occurring amongst the patient cohort.

Table 3 shows the diagnostic accuracy of the rule for cardiac events. Table 4 shows the diagnostic accuracy of the rule for cardiac events, including angioplasty and bypass surgery. Of those for early discharge, 24 had cardiac events and 13 had angioplasty or bypass at 30 days, compared to 91 and 41 , respectively, for those unsuitable for discharge. This gave the rule a sensitivity of $79.1 \%$ for cardiac events and $78.1 \%$ for cardiac events, including angioplasty and bypass. Specificity was $40.4 \%$ and $41 \%$, and NPV was $96.4 \%$ and $94.4 \%$, respectively.

Regarding the 24 patients whom the rule indicated were safe for early discharge but had cardiac events (Table 3), all 24 had no prior history of ischemic chest pain. Five were below 50 years of age, and 19 were above 50 years of age but had low-risk pain characteristics. Of the 19 with low-risk pain, 5 had an initial 


\begin{tabular}{|c|c|c|c|c|}
\hline Characteristics & $\begin{array}{c}\text { Total } \\
N=1690\end{array}$ & $\begin{array}{l}\text { Cardiac event (Yes) } \\
\qquad N=169\end{array}$ & $\begin{array}{l}\text { Cardiac event (No) } \\
\qquad N=1521\end{array}$ & $P$ value \\
\hline Mean age (SD) & $53.0(12.5)$ & $59.2(10.2)$ & $52.4(12.6)$ & $<0.001$ \\
\hline Male (\%) & $1000(59.2)$ & $126(74.6)$ & $874(57.5)$ & $<0.001$ \\
\hline \multicolumn{5}{|l|}{ Race (\%) } \\
\hline Chinese & 1179 (69.8) & $123(72.2)$ & 1057 (69.5) & 0.667 \\
\hline Malay & $191(11.3)$ & $20(11.8)$ & $171(11.2)$ & \\
\hline Indian & $292(17.3)$ & $26(15.4)$ & $266(17.5)$ & \\
\hline Others & $28(1.7)$ & $1(0.6)$ & $27(1.8)$ & \\
\hline \multicolumn{5}{|l|}{ Medical history (\%) } \\
\hline Diabetes & $289(17.1)$ & $51(30.2)$ & $238(15.6)$ & $<0.001$ \\
\hline Smokers & 555 (32.8) & $73(43.2)$ & $482(31.7)$ & 0.003 \\
\hline Hypertension & $693(41.0)$ & $85(50.3)$ & $608(40)$ & 0.01 \\
\hline Dyslipidemia & 467 (27.6) & $52(30.8)$ & $415(27.3)$ & 0.248 \\
\hline Myocardial infarction & $23(1.4)$ & $7(4.1)$ & $16(1.1)$ & 0.005 \\
\hline Family history of AMI & 185 (10.9) & $13(7.7)$ & $172(11.3)$ & 0.194 \\
\hline Congestive heart failure & $2(0.1)$ & $0(0)$ & $2(0.1)$ & NA \\
\hline CABG & $11(0.7)$ & $1(0.6)$ & $10(0.7)$ & 1 \\
\hline Angioplasty & $24(1.4)$ & $4(2.4)$ & $20(1.3)$ & 0.291 \\
\hline IHD & $74(4.4)$ & $14(8.3)$ & $60(3.9)$ & 0.016 \\
\hline Stroke & $32(1.9)$ & $2(1.2)$ & $30(2)$ & 0.764 \\
\hline Peripheral vascular disease & $4(0.2)$ & $1(0.6)$ & $3(0.2)$ & 0.344 \\
\hline Previously prescribed nitrate & $67(4.0)$ & $5(3)$ & $62(4.1)$ & 0.287 \\
\hline \multicolumn{5}{|l|}{ ED presentation and investigation } \\
\hline Diagnostic impression of unstable angina (\%) & $26(1.5)$ & $7(4.1)$ & $19(1.2)$ & 0.011 \\
\hline $\begin{array}{l}\text { Time of most severe chest pain to time of } \\
\text { registration, median (IQR), minutes }\end{array}$ & $470(245,1440)$ & $497.5(240,1267.5)$ & $470(250,1495)$ & 0.466 \\
\hline Chest pain with radiation (\%) & $417(24.7)$ & $54(32)$ & $363(23.9)$ & 0.027 \\
\hline Chest pain with palpation (\%) & $73(4.3)$ & $4(2.4)$ & $69(4.5)$ & 0.151 \\
\hline Aggravated by breathing (\%) & $124(7.3)$ & $1(0.6)$ & $123(8.1)$ & 0.001 \\
\hline ST elevation (\%) & 537 (31.8) & $73(43.2)$ & $464(30.5)$ & 0.001 \\
\hline ST depression (\%) & $220(13)$ & $53(31.4)$ & $167(11)$ & $<0.01$ \\
\hline T wave inversion (\%) & 556 (32.9) & $79(46.7)$ & 477 (31.4) & $<0.01$ \\
\hline Mean HR (SD) & $77.1(14.7)$ & $75.4(16.1)$ & $77.3(14.5)$ & 0.049 \\
\hline Mean SBP (SD) & $143.5(26.6)$ & $150.0(29.2)$ & $142.8(26.2)$ & 0.002 \\
\hline Initial CK-MB <3.0 $\mu \mathrm{g} / \mathrm{L}(\%)$ & $1363(80.7)$ & $82(48.5)$ & $1281(84.2)$ & $<0.001$ \\
\hline Rise in CK-MB at $3 \mathrm{hrs}(\%)$ & $413(24.4)$ & $88(52.1)$ & $325(21.4)$ & $<0.001$ \\
\hline TnT $0 \mathrm{hr}<0.03 \mathrm{ng} / \mathrm{ml}$ & $1463(86.6)$ & $78(46.2)$ & $1385(91.1)$ & $<0.001$ \\
\hline Rise in TnT at $3 \mathrm{hrs}(\%)$ & $89(5.3)$ & $74(43.8)$ & $15(1)$ & $<0.001$ \\
\hline ECG changes (\%) & $1012(59.9)$ & $132(78.1)$ & $880(57.9)$ & $<0.001$ \\
\hline
\end{tabular}

TnT $<0.03 \mathrm{ng} / \mathrm{ml}$, and $14 \mathrm{had}$ an initial TnT $\geq 0.03 \mathrm{ng} / \mathrm{ml}$ but no serial change in ECG or rise in TnT from 0 to 3 hours after arrival.

\section{DISCUSSION}

In this study, we found that the VCP Rule had only moderate sensitivity and poor specificity for adverse cardiac events. With a NPV of less than $100 \%$, this means that a small proportion of patients sent home with early discharge would still have adverse cardiac events (this is, however, a common finding in most chest pain rules).

We found a lower sensitivity and negative predictive power than in the original VCP study, which was reported at $98.8 \%$ and $99.0 \%$, respectively. ${ }^{4}$ Greenslade et al.'s ${ }^{5}$ 


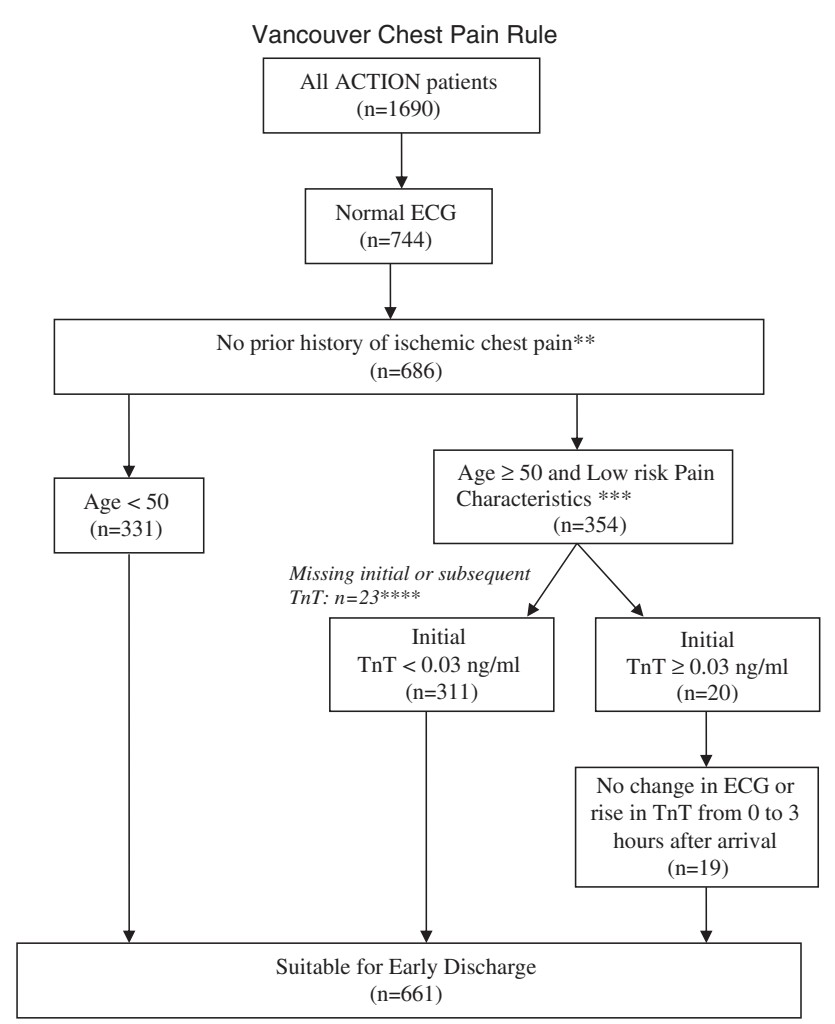

Figure 1. Chest pain early discharge rule.

T-wave flattening is the only acceptable ST-T abnormality. Note: Patients with suspicion of other causes of chest pain (e.g., pulmonary embolus, aortic dissection) should be investigated independent of this clinical prediction rule. ** Prior ischemic chest pain is defined as a past known diagnosis of $\mathrm{MI}$ or angina, previously prescribed nitroglycerine or a clear history of effort-related angina. ***Low risk Pain Characteristics is defined as pain not radiating (arm/neck/jaw) OR increasing with a deep breath OR increasing with palpation

****All cases with missing data at decision points are assigned to "Unsuitable for early discharge."

Table 2. 7-day and 30-day cardiac events of a patient cohort

\begin{tabular}{|c|c|c|}
\hline Outcome, $n(\%)$ & $\begin{array}{c}\text { 7-day } \\
N=1690\end{array}$ & $\begin{array}{c}\text { 30-day } \\
N=1690\end{array}$ \\
\hline Death & $1(0.1)$ & $1(0.1)$ \\
\hline Ventricular fibrillation & $0(0)$ & $0(0.0)$ \\
\hline AMI & $110(6.5)$ & $114(6.7)$ \\
\hline Cardiogenic shock & $1(0.1)$ & $2(0.1)$ \\
\hline Acute pulmonary edema & $1(0.1)$ & $1(0.1)$ \\
\hline PTCA & 77 (4.6) & $104(6.2)$ \\
\hline CABG & $13(0.8)$ & $29(1.7)$ \\
\hline
\end{tabular}

$\mathrm{AMI}=$ acute myocardial infarction; PTCA = percutaneous transcoronary angioplasty $;$ $\mathrm{CABG}=$ coronary artery bypass graft.

study, which replaced CK-MB with troponin as the cardiac enzyme marker in the original VCP Rule, also reported higher sensitivity (91\%) but similar NPV

\begin{tabular}{|c|c|c|}
\hline & $\begin{array}{l}\text { Cardiac event } \\
\text { (Yes) }\end{array}$ & $\begin{array}{c}\text { Cardiac } \\
\text { event (No) }\end{array}$ \\
\hline $\begin{array}{l}\text { Unsuitable for early discharge } \\
(n=1029)\end{array}$ & 91 & 938 \\
\hline $\begin{array}{l}\text { Meet rule criteria for early } \\
\text { discharge }(n=661)\end{array}$ & 24 & 637 \\
\hline Sensitivity $(95 \% \mathrm{Cl})$ & \multicolumn{2}{|c|}{$79.1(70.6-86.1)$} \\
\hline Specificity $(95 \% \mathrm{Cl})$ & \multicolumn{2}{|c|}{$40.4(38.0-42.9)$} \\
\hline Positive predictive value $(95 \% \mathrm{Cl})$ & \multicolumn{2}{|c|}{$8.8(7.2-10.7)$} \\
\hline Negative predictive value $(95 \% \mathrm{Cl})$ & \multicolumn{2}{|c|}{$96.4(94.6-97.7)$} \\
\hline Likelihood ratio+ & \multicolumn{2}{|c|}{$1.33(1.20-1.47)$} \\
\hline $\begin{array}{l}\text { Area under the ROC curve }(95 \% \mathrm{Cl}) \\
\text { (c statistic) }\end{array}$ & \multirow{2}{*}{\multicolumn{2}{|c|}{$0.60(0.56-0.64)$}} \\
\hline ROC, receiver operating characteristic & & \\
\hline
\end{tabular}

\begin{tabular}{|c|c|c|}
\hline & $\begin{array}{c}\text { Cardiac event, } \\
\text { PTCA, CABG (Yes) }\end{array}$ & $\begin{array}{c}\text { Cardiac event, } \\
\text { PTCA, CABG (No) }\end{array}$ \\
\hline $\begin{array}{l}\text { Unsuitable for early } \\
\text { discharge }(n=1029)\end{array}$ & 132 & 897 \\
\hline $\begin{array}{l}\text { Meet rule criteria for } \\
\text { early discharge } \\
(n=661)\end{array}$ & 37 & 624 \\
\hline Sensitivity (95\% Cl) & \multicolumn{2}{|c|}{$78.1(71.1-84.1)$} \\
\hline Specificity (95\% Cl) & \multicolumn{2}{|c|}{$41(38.5-43.5)$} \\
\hline $\begin{array}{l}\text { Positive predictive } \\
\text { value }(95 \% \mathrm{Cl})\end{array}$ & \multicolumn{2}{|c|}{$12.8(10.8-15.0)$} \\
\hline $\begin{array}{l}\text { Negative predictive } \\
\text { value }(95 \% \mathrm{Cl})\end{array}$ & \multicolumn{2}{|c|}{$94.4(92.4-96)$} \\
\hline Likelihood ratio + & \multicolumn{2}{|c|}{$1.32(1.20-1.45)$} \\
\hline $\begin{array}{l}\text { Area under the ROC } \\
\text { curve } \\
\text { (c statistic) } \\
\text { ROC, receiver operatir }\end{array}$ & \multicolumn{2}{|c|}{$0.60(0.56-0.63)$} \\
\hline
\end{tabular}

(94.4\%) as our study. Specificity was higher in our study as compared to Christenson's ${ }^{4}$ and Greenslade's 5 studies.

Methodologically, our study is similar to Cullen's and Scheuermeyer's studies where the new VCP Rule with troponin assay was retrospectively applied to the chest pain cohort. Despite the similarity in methodology, our study achieved a much lower sensitivity but higher specificity as compared to Cullen's ${ }^{6}$ (sensitivity: $99.1 \%$, specificity: $16.3 \%$ ) and Scheuermeyer's ${ }^{7}$ (sensitivity: $99.2 \%$, specificity: $23.4 \%$ ). Several reasons may explain 
the differences in results between our study and theirs such as recruitment hours, outcomes definition, and ethnic differences in the population. In Cullen's and Scheuermeyer's studies, patients were recruited during office hours only (weekdays, 0800-1700) or during the day and evening (1100-1900); our study's recruitment was from Sunday 0800 to Saturday 0359. There may be differences in standard of care (e.g., availability of physicians/nurses in the chest pain unit, quality of care associated with staff fatigue) and subsequently outcomes when patients present during after-office hours as seen in studies examining mortality rates in patients with AMI who presented after office-hours. ${ }^{13}$ Also, there may be differences between the patient population in this study and the patients in both Scheuermeyer's ${ }^{7}$ and Cullen's $^{6}$ validations. Specifically, the exclusion of patients with known coronary disease and those with high-risk angina presentation might be different from practice in North America. These should be kept in mind when comparing results between studies.

It is also important to point out that, in these previous studies, the main outcome measure was a 30-day diagnosis of AMI or definite unstable angina. ${ }^{4,6,7}$ The diagnosis of definite unstable angina in Christenson's study required rest pain greater than or equal to 20 minutes, and at least one of the following related to the presenting symptoms: 1) troponin increase 0.1 to $0.99 \mathrm{mg} / \mathrm{L}, 2$ ) dynamic ECG changes consistent with ischemia in two contiguous leads (dynamic ST depression $0.5 \mathrm{~mm}$ or dynamic deep T-wave inversion), 3) a coronary angiogram with greater than $70 \%$ lesion plus hospital admission for ACS, or 4) a positive stress test result (radionuclide scan echo or ECG stress test) plus admission for ACS. ${ }^{4}$ For our study, we have chosen to use proven adverse cardiac events as our main outcome measure, which we felt was more conservative and clinically important. Despite this, we note the relatively poorer performance of the rule in our population. As far as we know, none of the revascularizations in our study were elective/previously planned procedures, because patients were excluded if they had a previous angiogram or SMPI/echo test within 18 months.

Lastly, previous studies ${ }^{14}$ have suggested that ethnic differences exist in the presentation, diagnosis, treatment, and responses for cardiovascular diseases. Chaturvedi ${ }^{14}$ observed that accurate diagnosis of cardiovascular causes for upper body discomfort in South Asians was more challenging as compared to Europeans; South Asians were more frequently investigated for upper gastrointestinal disorders. South Asians with AMI were also more likely to be categorized as non-typical than Europeans. Self-reported symptoms such as pain increasing with palpation might be highly subjective and influenced by cultural factors. Ischemic heart disease also tended to occur at a younger age in South Asians as compared to Europeans, and apart from conventional risk factors (e.g., smoking, obesity), glucose intolerance, waist-to-hip ratio, fasting triglyceride, and insulin were also found to be predictors of ischemic heart disease in South Asians. ${ }^{14}$ These factors may suggest that using history of ischemic chest pain, low-risk pain characteristics in the VCP Rule may not be most suited for an Asian population.

Patients with chest pain of uncertain origin often undergo a period of observation varying from 6 to 12 hours, serial cardiac enzyme sampling, ${ }^{15-19}$ ECGs, and possibly provocative stress testing. ${ }^{20}$ As many hospitals face situations with decreased inpatient capacity resulting in "bed block," ${ }^{21}$ management of chest pain in the ED can possibly decrease in-hospital admissions for evaluation of chest pain. ${ }^{22}$ However, the pressures of ED overcrowding $^{21,23-28}$ mean that $\mathrm{ED}$ resources can become stretched due to the lengthy and costly evaluations of chest pain patients in order to "rule out" ACS.

It is in such a setting that accelerated chest pain assessment protocols are attractive. ${ }^{4,29,30}$ The challenge is to safely identify the subset of low-risk patients who do not require such lengthy and costly rule-out evaluations. ${ }^{1,31,32}$ The VCP Rule shows some promise in identifying this group. However, the rule is still limited by the requirement for sampling of cardiac enzymes at 2 hours post initial evaluation, which practically means that the patient needs to be observed in the ED for a minimum of a 3- to 4-hour period.

Limitations of this study include that, although it was prospective data collection, application of the VCP Rule was based on a hypothetical application of this rule in our population. This population was also highly selected in that patients with "high risk" symptoms would usually be directly admitted to the hospital, based on symptoms alone, irrespective of their laboratory findings, and would not have been included in this study population. Also, there may be some confounding due to the fact that, in the data set, two-thirds of the validation cohort had undergone SMPI within 24 hours of ED discharge (58\% of patients who did not meet the criteria for early discharge underwent SMPI, whereas $62 \%$ of patients who met the criteria for early discharge underwent SMPI). However, we feel that this actually 
increases the validity of the study findings, because we have definitive testing and outcomes for most of the data set. The number of missing data was relatively small and would not have affected the analysis. There were 23 cases with "missing" initial or subsequent TnT, usually related to delayed blood draw. These cases with missing information were treated as "not suitable" for early discharge based on a conservative approach. Also, we note that this study was performed using the previous generation of TnT assay. The performance of the VCP Rule might be improved by the new high sensitivity troponin assays currently available.

Despite the limitations discussed, this study demonstrates the utility of validating clinical scoring systems in local settings. We intend to follow up with a prospective observational study, likely modifying the new VCP Rule and comparing with other possible clinical rules. $^{33,34}$ This could be in combination with pointof-care testing. However, these rules may have more utility when combined with clinical pretest probabilities as indicated by our study.

\section{CONCLUSION}

We found the VCP Rule to have only moderate sensitivity and poor specificity for adverse cardiac events in our population. With an NPV of less than $100 \%$, this means that a small proportion of patients sent home with early discharge would still have adverse cardiac events. Further study is needed regarding the utility of the rule in clinical practice.

Financial Support: This study was supported by grants from the National Medical Research Council, Ministry of Health, Singapore [Grant Numbers NMRC/0517/2001].

Competing interests: None declared.

\section{REFERENCES}

1. Amsterdam EA, Lewis WR, Yadlapalli S. Evaluation of lowrisk patients with chest pain in the emergency department: value and limitations of recent methods. Cardiol Rev 1999; 7:17-26.

2. Pope JH, Aufderheide TP, Ruthazer R, et al. Missed diagnoses of acute cardiac ischemia in the emergency department. NE7M 2000;342:1163-70.

3. McCarthy BD, Beshansky JR, D'Agostino RB, et al. Missed diagnoses of acute myocardial infarction in the emergency department: results from a multicenter study. Ann Emerg Med 1993;22:579-82.
4. Christenson J, Innes G, McKnight D, et al. A clinical prediction rule for early discharge of patients with chest pain. Ann Emerg Med 2006;47:1-10.

5. Greenslade JH, Cullen L, Than M, et al. Validation of the Vancouver Chest Pain Rule using troponin as the only biomarker: a prospective cohort study. Am 7 Emerg Med 2013;31:1103-7.

6. Cullen L, Greenslade JH, Than M, et al. The new Vancouver Chest Pain Rule using troponin as the only biomarker: an external validation study. Am 7 Emerg Med 2014;32:129-34.

7. Scheuermeyer FX, Wong H, Yu E, et al. Development and validation of a prediction rule for early discharge of low-risk emergency department patients with potential ischemic chest pain. C7EM 2014;16:106-19.

8. Than M, Herbert M, Flaws D, et al. What is an acceptable risk of major adverse cardiac event in chest pain patients soon after discharge from the emergency department? A clinical survey. Int 7 Cardiol 2013;166:752-4.

9. MacGougan CK, Christenson JM, Innes GD, et al. Emergency physicians' attitudes toward a clinical prediction rule for the identification and early discharge of low risk patients with chest discomfort. CFEM 2001;3:89-94.

10. Kavsak PA, Worster A. For a rapid diagnosis of acute myocardial infarction, a sensitive troponin assay is needed in the near-patient testing setting. Expert Rev Cardiovasc Ther 2012;10:309-12.

11. Than M, Cullen L, Aldous S, et al. 2-hour accelerated diagnostic protocol to assess patients with chest pain symptoms using contemporary troponins as the only biomarker: the ADAPT trial. FACC 2012;59:2091-8.

12. Lim SH, Anantharaman V, Sundram F, et al. Stress myocardial perfusion imaging for the evaluation and triage of chest pain in the emergency department: a randomized controlled trial. 7 F Nucl Cardiol 2013;20:1002-12.

13. Pirrallo RG, Aufderheide TP, Provo TA, et al. Effect of an inspiratory impedance threshold device on hemodynamics during conventional manual cardiopulmonary resuscitation. Resuscitation 2005;66:13-20.

14. Chaturvedi N. Ethnic differences in cardiovascular disease. Heart 2003;89:681-6.

15. Ellestad MH, Startt-Selvester R, Stanton E, et al. The utility of four biochemical markers in the triage of chest pain patients. Cardiology 2000;93:242-8.

16. Gibler WB, Lewis LM, Erb RE, et al. Early detection of acute myocardial infarction in patients presenting with chest pain and nondiagnostic ecgs: serial CK-MB sampling in the emergency department. Ann Emerg Med 1990;19:1359-66.

17. Herkner H, Waldenhofer U, Laggner AN, et al. Clinical application of rapid quantitative determination of cardiac troponin- $\mathrm{T}$ in an emergency department setting. Resuscitation 2001;49:259-64.

18. Ordonez-Llanos J, Santalo-Bel M, Merce-Muntanola J, et al. Risk stratification of chest pain patients by point-ofcare cardiac troponin $\mathrm{T}$ and myoglobin measured in the emergency department. Clin Chim Acta 2006;365:93-7.

19. Peacock WI, Emerman CL, McErlean ES, et al. Prediction of short- and long-term outcomes by troponin $\mathrm{T}$ levels in low-risk patients evaluated for acute coronary syndromes. Ann Emerg Med 2000;35:213-20. 
20. Schaeffer MW, Brennan TD, Hughes JA, et al. Resting radionuclide myocardial perfusion imaging in a chest pain center including an overnight delayed image acquisition protocol. 7 Nucl Med Technol 2007;35:242-5.

21. Trzeciak S, Rivers EP. Emergency department overcrowding in the United States: an emerging threat to patient safety and public health. Emerg Med 7 2003;20:402-5.

22. Goldman L. Using prediction models and cost-effectiveness analysis to improve clinical decisions: emergency department patients with acute chest pain. Proc Assoc Am Physicians 1995;107:329-33.

23. Bradley VM. Placing emergency department crowding on the decision agenda. 7 Emerg Nurs 2005;31:247-58.

24. Dickinson G. Emergency department overcrowding. CMAf 1989;140:270-1.

25. Kunz Howard P. Overcrowding: not just an emergency department issue. 7 Emerg Nurs 2005;31:227-8.

26. Laskowski-Jones L. Starling's curve: a way to conceptualize emergency department overcrowding. 7 Emerg Nurs 2005;31:229-30.

27. Lynn SG, Kellermann AL. Critical decision making: managing the emergency department in an overcrowded hospital. Ann Emerg Med 1991;20:287-92.

28. Walters SD. Is booming demand dooming emergency department? Mich Hosp 1990;26:4-9.
29. Aroney CN, Dunlevie HL, Bett JH. Use of an accelerated chest pain assessment protocol in patients at intermediate risk of adverse cardiac events. Med 7 Aust 2003;178:370-4.

30. Grzybowski M, Zalenski RJ, Ross MA, et al. A prediction model for prehospital triage of patients with suspected cardiac ischemia. $\mathcal{F}$ Electrocardiol 2000;33 (Suppl):253-8.

31. Schillinger M, Sodeck G, Meron G, et al. Acute chest painidentification of patients at low risk for coronary events. The impact of symptoms, medical history and risk factors. Wien Klin Wochenschr 2004;116:83-9.

32. Selker HP, Beshansky JR, Griffith JL, et al. Use of the acute cardiac ischemia time-insensitive predictive instrument (ACI-TIPI) to assist with triage of patients with chest pain or other symptoms suggestive of acute cardiac ischemia. A multicenter, controlled clinical trial. Ann Intern Med 1998;129:845-55.

33. Antman EM, Cohen M, Bernink PJ, et al. The TIMI risk score for unstable angina/non-ST elevation MI: a method for prognostication and therapeutic decision making. $7 A M A$ 2000;284:835-42.

34. Backus BE, Six AJ, Kelder JC, et al. A prospective validation of the heart score for chest pain patients at the emergency department. Int 7 Cardiol 2013;168:2153-8. 